\title{
Morphology of bar-built estuaries: empirical relation between planform shape and depth distribution
}

\author{
Jasper R. F. W. Leuven, Sanja Selaković, and Maarten G. Kleinhans \\ Faculty of Geosciences, Utrecht University, Princetonlaan 8A, 3584 CB, Utrecht, the Netherlands \\ Correspondence: Jasper R. F. W. Leuven (j.r.f.w.leuven@uu.nl)
}

Received: 15 February 2018 - Discussion started: 22 February 2018

Revised: 11 July 2018 - Accepted: 28 August 2018 - Published: 11 September 2018

\begin{abstract}
Fluvial-tidal transitions in estuaries are used as major shipping fairways and are characterised by complex bar and channel patterns with a large biodiversity. Habitat suitability assessment and the study of interactions between morphology and ecology therefore require bathymetric data. While imagery offers data of planform estuary dimensions, only for a few natural estuaries are bathymetries available. Here we study the empirical relation between along-channel planform geometry, obtained as the outline from imagery, and hypsometry, which characterises the distribution of along-channel and cross-channel bed levels. We fitted the original function of Strahler (1952) to bathymetric data along four natural estuaries. Comparison to planform estuary shape shows that hypsometry is concave at narrow sections with large channels, while complex bar morphology results in more convex hypsometry. We found an empirical relation between the hypsometric function shape and the degree to which the estuary width deviates from an ideal convergent estuary, which is calculated from river width and mouth width. This implies that the occurring bed-level distributions depend on inherited Holocene topography and lithology. Our new empirical function predicts hypsometry and along-channel variation in intertidal and subtidal width. A combination with the tidal amplitude allows for an estimate of inundation duration. The validation of the results on available bathymetry shows that predictions of intertidal and subtidal area are accurate within a factor of 2 for estuaries of different size and character. Locations with major human influence deviate from the general trends because dredging, dumping, land reclamation and other engineering measures cause local deviations from the expected bed-level distributions. The bathymetry predictor can be used to characterise and predict estuarine subtidal and intertidal morphology in data-poor environments.
\end{abstract}

\section{Introduction}

Estuaries develop as a result of dynamic interactions between hydrodynamic conditions, sediment supply, underlying geology and ecological environment (Townend, 2012; de Haas et al., 2017). One model for the resulting morphology is that of the "ideal estuary" that is hypothesised to have alongchannel uniform tidal range, constant depth and current velocity, and a channel width that exponentially converges in the landward direction such that the loss of tidal energy by friction is balanced by the gain in tidal energy by convergence (Savenije, 2006, 2015; Townend, 2012; Dronkers, 2017). One would expect that in this case the along-channel variation in hypsometry is also negligible. However, natural estuaries deviate from ideal ones as a result of a varying degree of sediment supply, lack of time for adaptation and sea-level rise (Townend, 2012; de Haas et al., 2017), and locations wider than ideal are filled with tidal bars (Leuven et al., 2018a) (Fig. 1). Differences in bed-level profiles between ideal and non-ideal estuaries are further enhanced by damming, dredging, dumping, land reclamation and other human interference (e.g. O'Connor, 1987; Wang and Winterwerp, 2001; Lesourd et al., 2001; Jeuken and Wang, 2010; Wang et al., 2015). All these natural deviations from the ideal estuary mean that there is no straightforward relation 

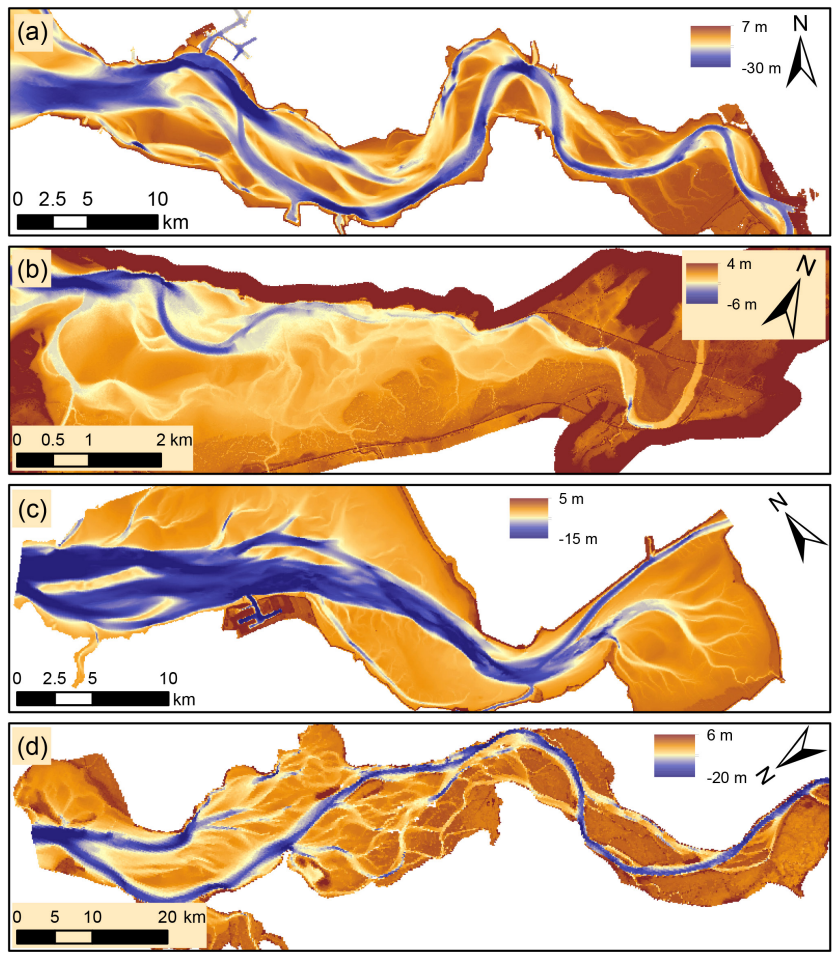

Figure 1. Bathymetry from (a) the Western Scheldt (NL), (b) the Dovey (Wales), (c) the Eems-Dollard (NL) and (d) the Columbia River Estuary (USA). Source: (a, c) Rijkswaterstaat (NL), (b) Natural Resources Wales, (d) Lower Columbia Estuary Partnership.

between the planform geometry of the estuary and the hypsometry or distribution of depths.

Hypsometry captures key elements of geomorphological features (Strahler, 1952; Boon and Byrne, 1981; Dieckmann et al., 1987; Kirby, 2000; Toffolon and Crosato, 2007; Townend, 2008, 2010; de Vet et al., 2017) (Fig. 2). The hypsometric method was developed by Strahler (1952) and Boon and Byrne (1981) to relate the planform area of a basin to elevation. Later the resulting functions were used to predict the influence of basin morphology on the asymmetry of the horizontal and vertical tides, to predict flood or ebb dominance and maturity of an estuary (Boon and Byrne, 1981; Wang et al., 2002; Moore et al., 2009; Friedrichs, 2010), and to characterise the trend of salt marsh development (Gardiner et al., 2011; Hu et al., 2015). Furthermore, hypsometry was used as a data reduction method to characterise entire reaches spanning bars and channels in estuaries (Toffolon and Crosato, 2007) and shapes of individual tidal bar tops (de Vet et al., 2017). Hypsometry has also been used to describe the dimensions of channels and tidal flats in an idealised model (Townend, 2010). In the latter, a parabolic shape was prescribed for the low water channel, a linear profile for the intertidal low zone and a convex profile for the intertidal high zone. While these profiles are valid for perfectly con- verging channels, it is unknown to what extent they are applicable to estuaries with irregular planforms and whether the currently assumed profiles are valid to assess flood or ebb dominance. Hypsometric profiles and derived inundation duration are also relevant indicators for habitat composition and future transitions from mudflat to salt marsh (Townend, 2008). To predict and characterise the morphology and assess habitat area, we need along-channel and cross-channel bedlevel predictions for systems without measured bathymetry (Wolanski and Elliott, 2015).

For only a few natural estuaries is bathymetry available, which leaves many alluvial estuaries with irregular planforms from all around the world underinvestigated. However, many estuaries are visible in detail on satellite imagery, which raises the question of whether there is a relation between planform geometry and depth distribution. Such a relation is known to exist in rivers in the form of hydraulic geometry depending on bar pattern and meander pool depths depending on planform channel curvature (e.g. Kleinhans and van den Berg, 2011; van de Lageweg et al., 2016). Therefore, it seems likely that such a relation between the horizontal and vertical dimensions exists for sandy estuaries as well, but this is not reported in the literature. Morphological models can simulate 3-D bed levels with considerable accuracy (van der Wegen and Roelvink, 2008, 2012; van Maren et al., 2015; Braat et al., 2017), but these models are computationally intensive and need calibration and specification of initial and boundary conditions. To study unmapped systems for which only aerial photography is available, it would be useful to be able to estimate bed-level distributions from planform geometry. Here we investigate this relation.

Previously, we showed in Leuven et al. (2018a) how locations and widths of tidal bars can be predicted from the excess width, which is the local width of the estuary minus the ideal estuary width. The summed width of bars in each cross section was found to approximate the excess width. This theory describes bars as discrete recognisable elements truncated at low water level on what is essentially a continuous field of bed elevation that changes in the along-channel direction (Leuven et al., 2016). However, to predict morphology in more detail, predictions of along-channel and crosschannel bed elevations are required. While hypsometry can summarise bed elevation distribution as a cumulative profile, it is unknown whether the shape of the profile is predictable. Our hypothesis is that the along-channel variation in hypsometry depends on the degree to which an estuary deviates from its ideal shape. Therefore, we expect that locations with large excess width and thus a large summed width of bars have a more convex hypsometry (Fig. 3c, d). In the case of an ideal estuary with (almost) no bars (Fig. 3a, b), we expect concave hypsometry.

The aim of this paper is to investigate the relation between estuary planform outline and along-channel variation in hypsometry. To do so, first hypsometric curves are used to summarise the occurring bed elevations in a cumulative profile. 


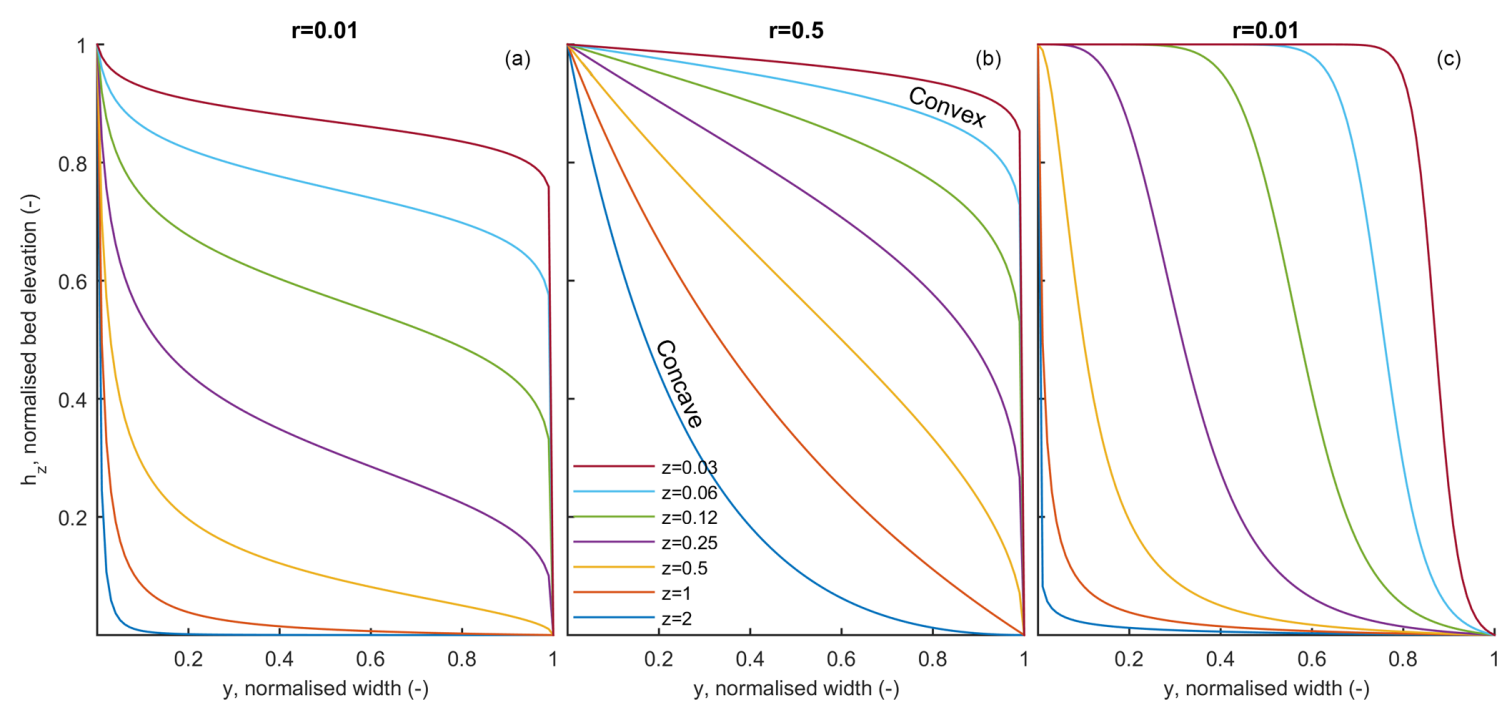

Figure 2. Hypsometric functions to describe morphological systems; modified from Strahler (1952). (a, b) Effect of $z$ values with the $r$ value kept constant. (c) Inverted version of the Strahler function (see Eq. 4).
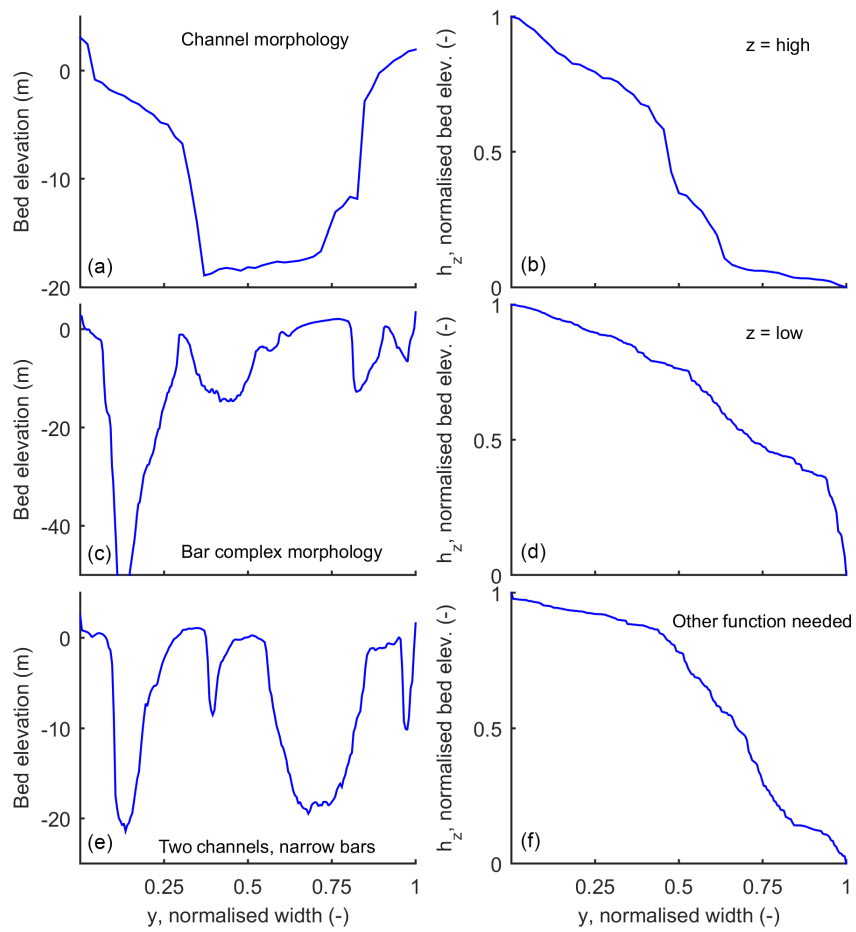

Figure 3. Example cross sections and hypsometry, suggesting that channel-dominated morphology (a, b) generally results in concave hypsometric functions (high $z$ value in Fig. 2), while bar complexes (c, d) generally result in convex hypsometry (low $z$ value in Fig. 2). In the case of narrow bars with a flat top and relatively steep transition from bar top to channel, the original hypsometry function by Strahler (1952) is less appropriate and the inverted function fits better.
Then, we use the original function of Strahler (1952) to fit the data obtained from the bathymetry of four estuaries (Fig. 1). In the results, we develop an empirical function to predict hypsometry. The quality and applications of the predictor are assessed in the discussion.

\section{Methods}

In this section, first, the definition of an ideal estuary is given with a description of how we derived a geometric property that characterises deviation from an ideal shape. Second, the general form of a hypsometric curve is described. Then, the available datasets that were used for curve fitting are given. Last, the methodology to fit a hypsometric function to bathymetry in systems is presented.

\subsection{Deviation from "ideal"}

A useful model to describe the morphology of estuaries is that of the "ideal estuary", in which the energy per unit width remains constant along-channel. The ideal state can be met when tidal range and tidal current are constant along-channel such that the loss of tidal energy by friction is balanced by the gain in tidal energy per unit width by channel convergence (Pillsbury, 1956; Dronkers, 2017). In the case that the depth is constant along-channel, the ideal estuary conditions are approximately met when the width is exponentially decreasing in the landward direction (Pillsbury, 1956; Langbein, 1963; Savenije, 2006, 2015; Toffolon and Lanzoni, 2010), which also implies an along-channel converging cross-sectional area. However, when depth and friction are not constant along-channel, for example linearly decreasing in the landward direction, less convergence in width is required to maintain constant energy per unit of width. 
Therefore, many natural estuaries are neither in equilibrium nor in a condition of constant tidal energy per unit width. They deviate from the ideal ones as a result of a varying degree of sediment supply, lack of time for adaptation to changing upstream conditions and sea-level rise (Townend, 2012; de Haas et al., 2017). Whether continued sedimentation would reform bar-built estuaries with irregular planforms into ideal estuaries remains an open question. While we expect a somewhat different degree of convergence such that the ideal state of constant energy per unit of width is approximately maintained, we do not study the deviation of this convergence length from that in ideal estuaries.

Ideally, we would assess the degree to which an estuary is in equilibrium from an aerial photograph. However, the only indicator derivable is channel width and thus deviation from a converging width profile. Therefore, in Leuven et al. (2018a), we defined the excess width, which is the local width of the estuary minus our approximation of the potential ideal estuary width. Here, the ideal estuary width is approximated as an exponential fit on the width of the mouth and the width of the landward river. While the empirical measure of "ideal width" should not be confused with the "ideal state" of an estuary, it is the only practical way to estimate deviation from an ideal estuary based on the estuary outline only. Moreover, it proved to be a good indicator of occurring bar patterns (Leuven et al., 2018a) and will therefore be applied in this paper to study hypsometries.

\subsection{General hypsometric curve}

In the past, multiple authors have proposed empirical relations for the hypsometric shape of terrestrial landscapes (Strahler, 1952) and (partially) submerged bodies (Boon and Byrne, 1981; Wang et al., 2002; Toffolon and Crosato, 2007) (see Townend, 2008, for a review). All equations, except for Wang et al. (2002), predict a fairly similar hypsometric curve based on the volume and height range of the landform (Townend, 2008). While it is of interest to use these empirical relations to predict the occurring altitude variation of a landform, the framework here is different. Here, we apply the general hypsometric curve to characterise the occurring crosssectional hypsometry along-channel. This approach is similar to the approach of Toffolon and Crosato (2007), who fitted a power function to 15 zones along the Western Scheldt. However, the zoned approach smooths out all the differences between bar complex and channel-dominated zones, which are of interest for this study. For this purpose, it is less relevant for which environment the hypsometric relation was proposed, as long as it is capable of describing the range of occurring hypsometries. For the case of the estuarine environment (Fig. 3), the hypsometric curve should be able to describe variations in concavity and variations in the slope of the curve at the inflection point. Here we use the original Strahler (1952) formulation, which is capable of doing so, but in principle any equation that fits well could be used.
Strahler (1952) formulated the general hypsometric curve as

$h_{z}=\left[\frac{r}{r-1}\right]^{z}\left[\frac{1}{(1-r) y+r}-1\right]^{z}$,

in which $h_{z}$ is the value of the bed elevation, above which fraction $y$ of the width profile occurs. In other words, $h_{z}$ is the proportion of total section height and $y$ the proportion of section width. $r$ sets the slope of the curve at the inflection point in a range of $0.01-0.50$, with sharper curves for lower values of $r$ (Fig. 2a, b). $z$ determines the concavity of the function in a range of $0.03-2$, with lower values giving a more convex profile and higher values giving a more concave profile (Strahler, 1952) (Fig. 2). Our approach changes the original definition of $r$ and $z$ to make them fitting parameters. It is expected that $z$ values depend on excess width because the fraction of the width occupied by bars becomes larger with excess width, resulting in a more convex hypsometric profile (Fig. 3c, d), or the presence of bars generates excess width.

Excess width is defined as the local width minus the ideal width, which is given by

$W_{\text {ideal }}(x)=W_{\mathrm{m}} \cdot e^{-x / L_{\mathrm{W}}}$,

in which $x$ is the distance from the mouth, $W_{\mathrm{m}}$ the width of the mouth and $L_{\mathrm{W}}$ is the width convergence length (Davies and Woodroffe, 2010), which can be obtained conservatively from a fit on the width of the mouth and the landward river width (Leuven et al., 2018a):

$L_{\mathrm{W}}=-s \frac{1}{\ln \left(\frac{W_{\mathrm{s}}}{W_{\mathrm{m}}}\right)}$,

in which $W_{\mathrm{m}}$ is the local width measured at the mouth of the estuary, $W_{\mathrm{s}}$ is the width measured at the landward side of the estuary and $s$ is the distance between these locations measured along the centreline. This practical method makes the convergence length somewhat sensitive to the selected position of the seaward and landward limit.

The landward limit was selected at the location where the width ceases to converge on an image at the resolution of the full estuary scale and the landward width was measured between the vegetated banks. The seaward limit was selected as the location with the minimum width in the case that bedrock geology, human engineering or a higher elevated spit confined the mouth because in these cases the minimum width limits the inflow of tidal prism. In other cases, the mouth was chosen at the point at which the first tidal flats were observed in the estuary or the sandy beach ends at the mouth of the estuary. However, when the mouth is chosen at a location where sand bars are present, the ideal width will be overestimated and the width of intertidal area underestimated. It is therefore recommended to either choose the mouth at a location where bars are absent or subtract the width of bars from the measured width at the mouth to obtain the ideal width profile. 


\subsection{Data availability and classification}

Detailed bathymetries were available for four systems: the Western Scheldt esturary (NL), the Dovey estuary (Wales), the Eems-Dollard estuary (NL) and the Columbia River Estuary (USA) (Fig. 1, Table 1). Data for the Western Scheldt and Eems were obtained from Rijkswaterstaat (NL), for the Dovey estuary from Natural Resources Wales and for the Columbia River Estuary from the Lower Columbia Estuary Partnership. Bed elevations were extracted from these bathymetries as follows. First, the estuary outline was digitised, excluding fully developed salt marshes, and subsequently a centreline was determined within this polygon (following the approach of Leuven et al., 2018a). Bed elevations were collected on equally spaced transects perpendicular to the centreline of the estuary. The bed levels extracted at each transect were subsequently sorted by bed-level value and made dimensionless to obtain hypsometric profiles (see Fig. 3 for examples).

We classified the transects by morphological characteristics and potential susceptibility to errors. The following morphological classes were used: mouth, bar junction, bar complex, narrow bar, point bar, channel, pioneer marsh. The mouth is the location where the estuary transitions into the sea. A bar junction is the most seaward or most landward tip of tidal bars. A bar complex, also called a compound bar, is a location where a large bar is dissected by barb channels (Leuven et al., 2016) or multiple smaller bars are present. Narrow bar is used when the bars present were narrow along their entire length and often also relatively flat on their top. Point bar is a bar in the inner bend of a large meander. Channel was assigned when bars were largely absent. Pioneer marsh was assigned when aerial photographs or bathymetry gave visual indications of initial marsh formation, such as the presence of small tidal creeks and pioneering vegetation. Fully developed marsh is excluded from the outline.

The following classes were used to indicate possible errors: the presence of harbours, major dredging locations, the presence of a sand spit, the presence of drainage channels for agriculture, constraints by hard layers, human engineering works. Either a locally deep channel or scour occurred at one of the sides of these transects or they lacked a natural transition from channel to estuary bank, thus ending in their deepest part on one side of the transect. Major dredging locations have unnaturally deeper channels and shallower bars, resulting in a hypsometric shape that is relatively flat in the highest and lowest part and is steep in between (Fig. 3e, f). Furthermore, in a few cases side channels were perpendicular to the orientation of the main channel of the estuary. This resulted in transects being along-channel of these side channels, which biases transect data towards larger depth and creates a flat hypsometric profile at the depth of the side channel.
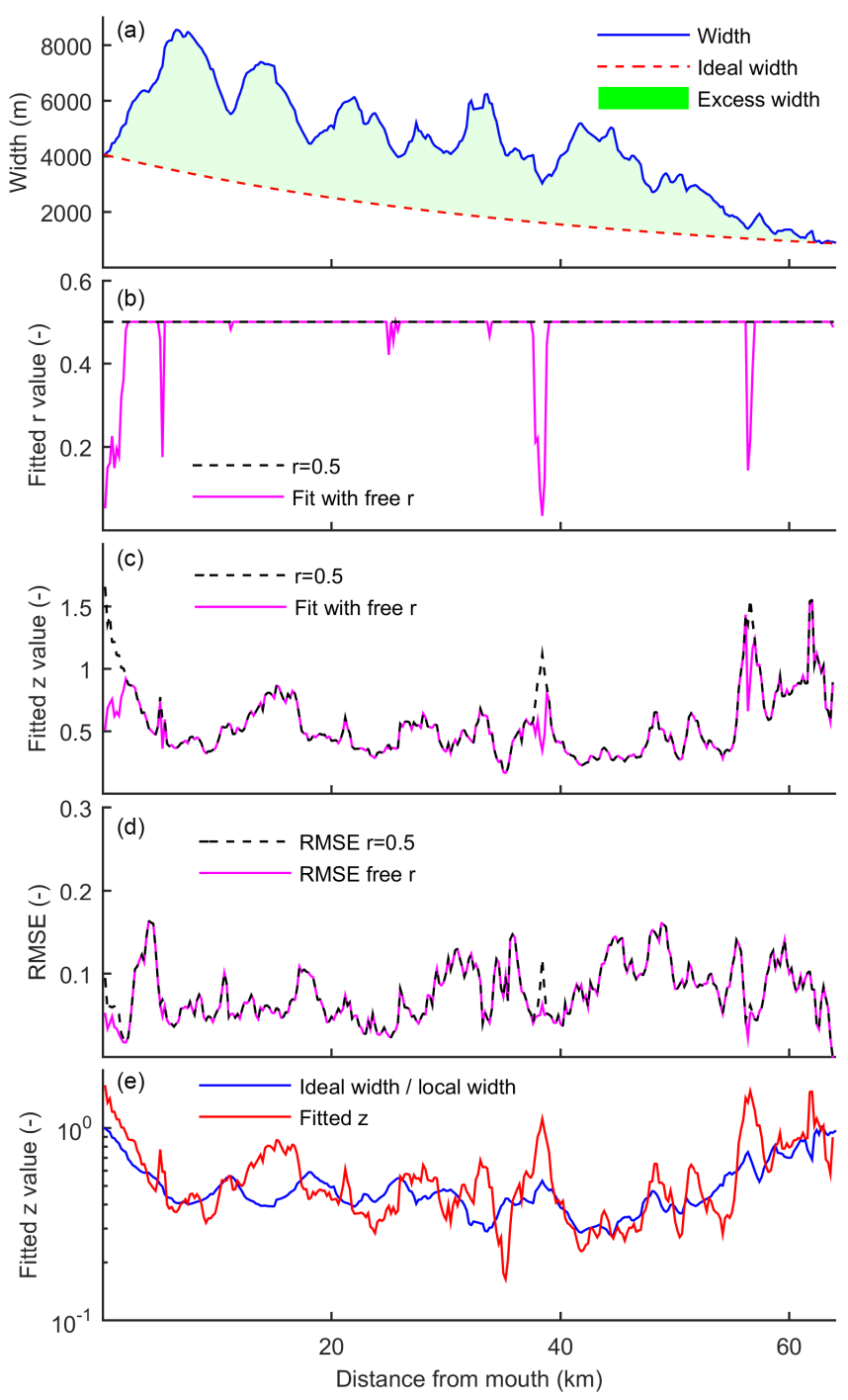

Figure 4. (a) Width along the Western Scheldt, with the maximum ideal converging width profile indicated. The green area is defined as the excess width cf. Leuven et al. (2018a). For each along-channel transect of the estuary, the optimal fit of $z$ and $r$ in the Strahler (1952) function (Fig. 2, Eq. 1) was determined. (b, c) Results for the Western Scheldt when both $z$ and $r$ are freely fitted (solid line) and the results when $r$ is fixed to a constant value of 0.5 (dashed line). (d) The quality of the fits remains about the same when $r$ is set to a fixed value of 0.5 as indicated by the root mean square error (RMSE). (e) Fitted $z$ values show similar trends as the ideal width divided by local width.

\subsection{Data processing}

Least-squares fits resulted in optimal values of $z$ and $r$ in Eq. (1) (Fig. 2) for each transect, using three different approaches. First, a regular least-squares curve fitting was used for $r$ and $z$, which resulted in along-channel varying values for $z$, but an almost entirely constant along-channel value for $r$ of 0.5 (Fig. 4b, c, solid lines). In the second approach we 
Table 1. Characteristics of the estuaries used in this study. $h_{m}$ is the depth at the mouth, $h_{r}$ is the depth at the landward river, $W_{m}$ is the width at the mouth, $W_{r}$ is the width at the landward river, $a$ is the tidal amplitude, "Area" is the surface area, "\% intertidal" is the percentage of intertidal area and $Q_{r}$ is the river discharge.

\begin{tabular}{lrrrrrrrr}
\hline & $h_{\mathrm{m}}(\mathrm{m})$ & $h_{\mathrm{r}}(\mathrm{m})$ & $W_{\mathrm{m}}(\mathrm{m})$ & $W_{\mathrm{r}}(\mathrm{m})$ & $2 a(\mathrm{~m})$ & Area $\left(\mathrm{km}^{2}\right)$ & $\%$ intertidal & $Q_{\mathrm{r}}\left(\mathrm{m}^{3} \mathrm{~s}^{-1}\right)$ \\
\hline Western Scheldt & 25 & 15 & 4500 & 350 & 5 & 300 & 20 & 100 \\
Columbia River & 40 & 20 & 4000 & 800 & 2.5 & 900 & 30 & 7000 \\
Dovey & 10 & 2 & 450 & 50 & 3 & 12 & 75 & 30 \\
Eems & 25 & 8 & 3500 & 350 & 3.5 & 260 & 30 & 80 \\
\hline
\end{tabular}

set $r$ to a constant value of 0.5 and only fitted to obtain $z$ (Fig. 4c, dashed line). We found that the quality of the fit was the same, as indicated by the root mean square error (RMSE) (Fig. 4d), and therefore apply this second approach in the remainder of this paper.

Locations where the RMSE was relatively large correspond to locations where major dredging occurred in the past century. This possibly resulted in a hypsometry characterised by a larger fraction of the width occupied by high tidal flats, a larger fraction of the width occupied by deep channels and a smaller fraction of the width occupied by the zone between channels and bars (Fig. 3e, f). Because the hypsometric curve at these locations deviated from the original Strahler function (Eq. 1), our third approach was to apply a modified function to find optimal values for $z$ and $r$. To do so, the original formulation of Strahler (1952) was inverted to allow for hypsometries that describe steep transitions from bar top to channel bottom because the original does not fit nearly as well:

$h_{z, \text { inv }}=\frac{\left[\frac{y^{1 / z}(1-r)}{r}+1\right]^{-1}-r}{1-r}$.

Applying this modified function resulted in better fits, but only at locations that were classified to be excluded because of possible errors. Therefore, results from this approach are not shown here and it is suggested to study the effect of dredging and dumping on hypsometry in more detail in future studies.

In principle, both the bed elevation $\left(h_{z}\right)$ and the width fraction $y$ in Eq. (1) are dimensionless. To compare the resulting predictions with measured values, the prediction needs to be dimensionalised. Values for $y$ are scaled with the local estuary width. We test three options to scale $h_{z}$. The first option is to scale $h_{z}$ between the highest bed elevation and lowest bed elevation in the given cross section, which is sensitive to the precise cut-off of the bathymetry. The second option is to scale $h_{z}$ between the local high water level (HWL) and the maximum estuary depth in that cross section, which is sensitive to bathymetric information that is usually not available in unmapped estuaries.

The third option requires a prediction of depth at the upstream or downstream boundary. Width-averaged depth profiles along estuaries are often (near) linear (Savenije, 2015;
Leuven et al., 2018a), which includes horizontal profiles with constant depth. Therefore, only the channel depth at the mouth of the estuary and at the upstream river have to be estimated, and subsequently a linear regression can be made. Channel depth at an upstream river $\left(h_{\mathrm{r}}\right)$ is estimated with hydraulic geometry relations (e.g. Leopold and Maddock Jr, 1953; Hey and Thorne, 1986): $h_{\mathrm{r}}=0.12 W_{\mathrm{r}}^{0.78}$. The depth at the mouth is estimated from relations between tidal prism and cross-sectional area (e.g. O'Brien, 1969; Eysink, 1990; Friedrichs, 1995; Lanzoni and D'Alpaos, 2015; Gisen and Savenije, 2015; Leuven et al., 2018a). Here we used

$h_{\mathrm{m}}=\frac{0.13 \times 10^{-3} P}{W_{\mathrm{m}}}$,

in which $P$ is the tidal prism, which can be estimated by multiplying the estuary surface area with the tidal range (Leuven et al., 2018a). This assumes a flat water surface elevation along the estuary and neglects portions of the estuary that might get dry during the tidal cycle (Boon, 1975). Locally, the maximum depth may be deeper or lower than predicted due to the presence of resistant layers in the subsurface or where banks are fixed or protected. While this may affect the accuracy of the locally predicted maximum channel depth, it has a minor effect on the calculations of subtidal and intertidal area. Moreover, the upper limit for dimensionalisation is chosen as the high water line, which implies that the supratidal area is not included in the predictions. We will show results with all methods, but only the third can be applied when information about depth is entirely lacking.

Statistical analyses in the remainder of the paper were approached as follows. In linear regressions, we minimised residuals in both the $x$ and $y$ directions. This results in regressions that are more robust than when residuals in only one direction are minimised. In the case that regressions are plotted, the legend will specify the multiplication factor that the confidence limits plot above or below the trend. $R^{2}$ values are given to indicate the variance around the regression. In cases in which the quality of the correlation between two alongchannel profiles is assessed, we used the Pearson productmoment correlation coefficient $(r)$. 


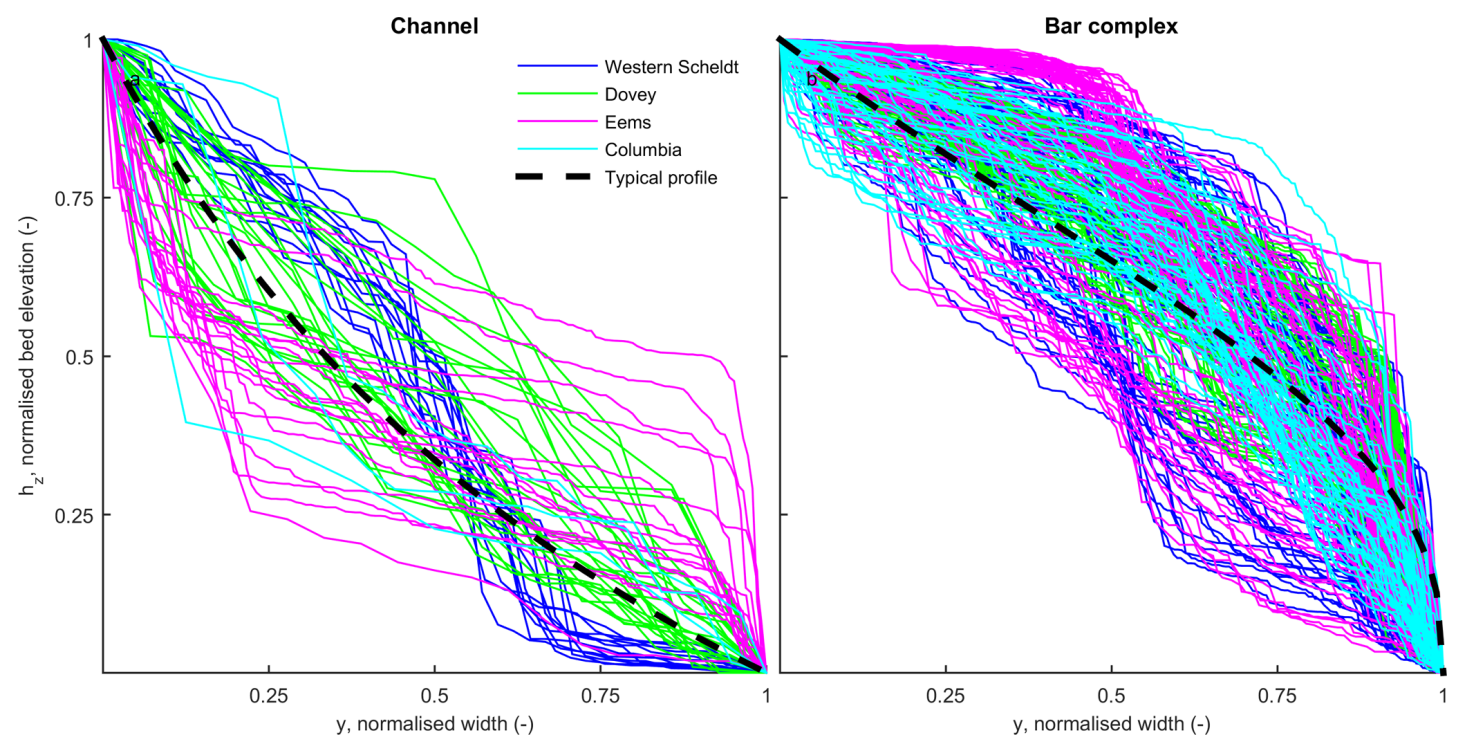

Figure 5. Hypsometric curves as extracted from bathymetry in the Western Scheldt, Dovey, Eems and Columbia River. Cross-sectional profiles were extracted along the centreline (Sect. 2.3) and were subsequently classified as channel when sand bars were (mostly) absent and as bar complex when one larger bar dissected by barb channels or multiple smaller bars was present. Channel-dominated morphology generally results in concave hypsometric profiles (a) and bar complexes in convex profiles (b).

\section{Results}

We found a strong relation between along-channel variation in hypsometry and the degree to which an estuary deviates from its ideal shape. Below, we will first show how the hypsometry of typical channel morphology deviates from that of bar complexes. Subsequently, the data are presented per system and classified on their morphology and potential for errors due to human interference, method and other causes. Then we combine all data to derive an empirical relation to predict hypsometry. Last, we apply this relation to predict the along-channel variation in intertidal and subtidal width and validate the results with measurements from bathymetry.

\subsection{Empirical relation between morphology and hypsometry}

As hypothesised, it is indeed observed that channeldominated morphology results in more concave hypsometry profiles (high $z$ value), while bar complex morphology results in more convex hypsometry (low $z$ value) (Fig. 5). Values for $z$ in Eq. (1) range from 0.83 to 1.14 for channels, with an average value of 1.0. In contrast, $z$ ranges from 0.36 to 0.41 for bar complexes, with an average of 0.39 .

Clustering of morphological classes strongly suggests a relation between hypsometry and planform estuary shape (Fig. 6). Mouth and channel-dominated morphologies typically plot at the right-hand side of the plots in Fig. 6a, c, e and $\mathrm{g}$, thus being locations close to ideal width. In the case of the Western Scheldt this results in the highest values of $z$. In the case of the Dovey and Columbia River, the mouth region was respectively influenced by a spit and human engineering, which resulted in the formation of tidal flats on the side and thus led to a lower $z$ value.

Bar complexes occur at the other end of the spectrum; these locations are generally much wider than the ideal shape and are characterised by hypsometries with a $z$ value well below 1 . Bar junctions, as well as narrow bars, are generally found at the transition from channel-dominated morphology to bar complex morphology and therefore also occur between these types in the plots. The point bar in the Western Scheldt (the Plaat van Ossenisse) shows hypsometry comparable to bar complexes (Fig. 6a), which reflects the complex history of formation by multiple bar amalgamations. Also, the locations in the Columbia River where pioneer marsh is present show the same trend as the locations where unvegetated bar complexes occur (Fig. 6g).

In a few cases, the transects used to extract bathymetry were not perpendicular to the main channel of the estuary. For example, landward and seaward of the point bar in the Western Scheldt (Plaat van Ossenisse) transects were inclined, covering a larger part of the channel than perpendicular transects, resulting in higher $z$ values as a consequence of the apparent channel-dominated morphology. Immediately landward of the spit in the Dovey, transects are almost parallel to the shallow side channel. Fitting hypsometry at these locations resulted in relatively low $z$ values because it is a relatively shallow side channel.

For the Western Scheldt and Eems it is known at which locations major dredging and dumping takes place (e.g. Swinkels et al., 2009; Jeuken and Wang, 2010; Bolle et al., 2010; Dam et al., 2015; Plancke and Vos, 2016). Even though 


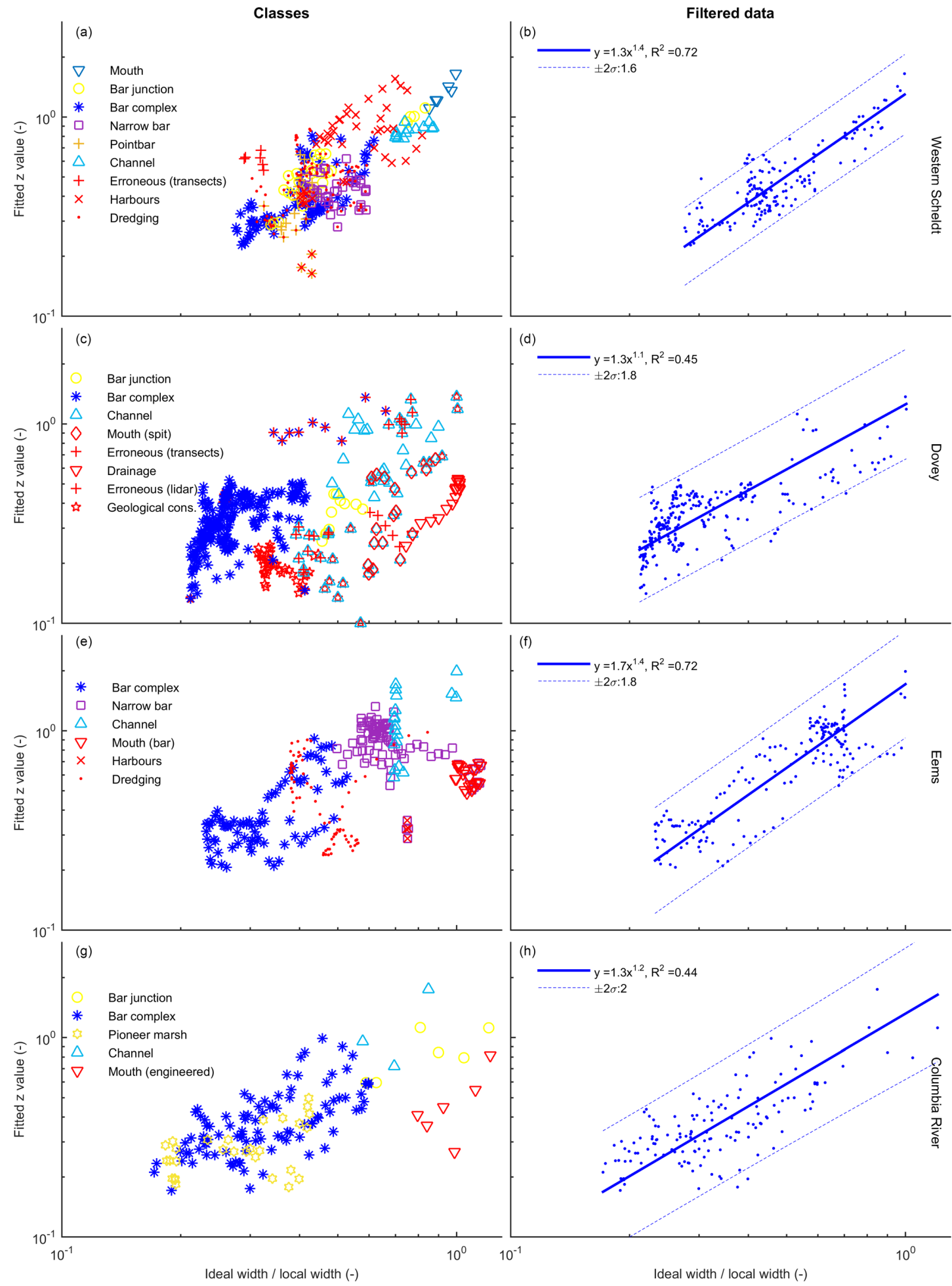

Figure 6. Results of hypsometry fitting in which clustering indicates a relation to planform geometry. (a, c, e, g) $z$ values were fitted for cross-channel transects in the bathymetry of four estuaries and plotted by morphological classification. (b, d, f, h) Regressions for $z$ value as a function of ideal width divided by local width. Data points that were influenced by human interference, bedrock geology, or errors in methodology or data, indicated in red (a, $, \mathbf{e}, \mathbf{e}, \mathbf{g})$, were excluded. Confidence limits are plotted at 2 standard deviations above and below the regression and their multiplication factor compared to the trend is given in the legend. 


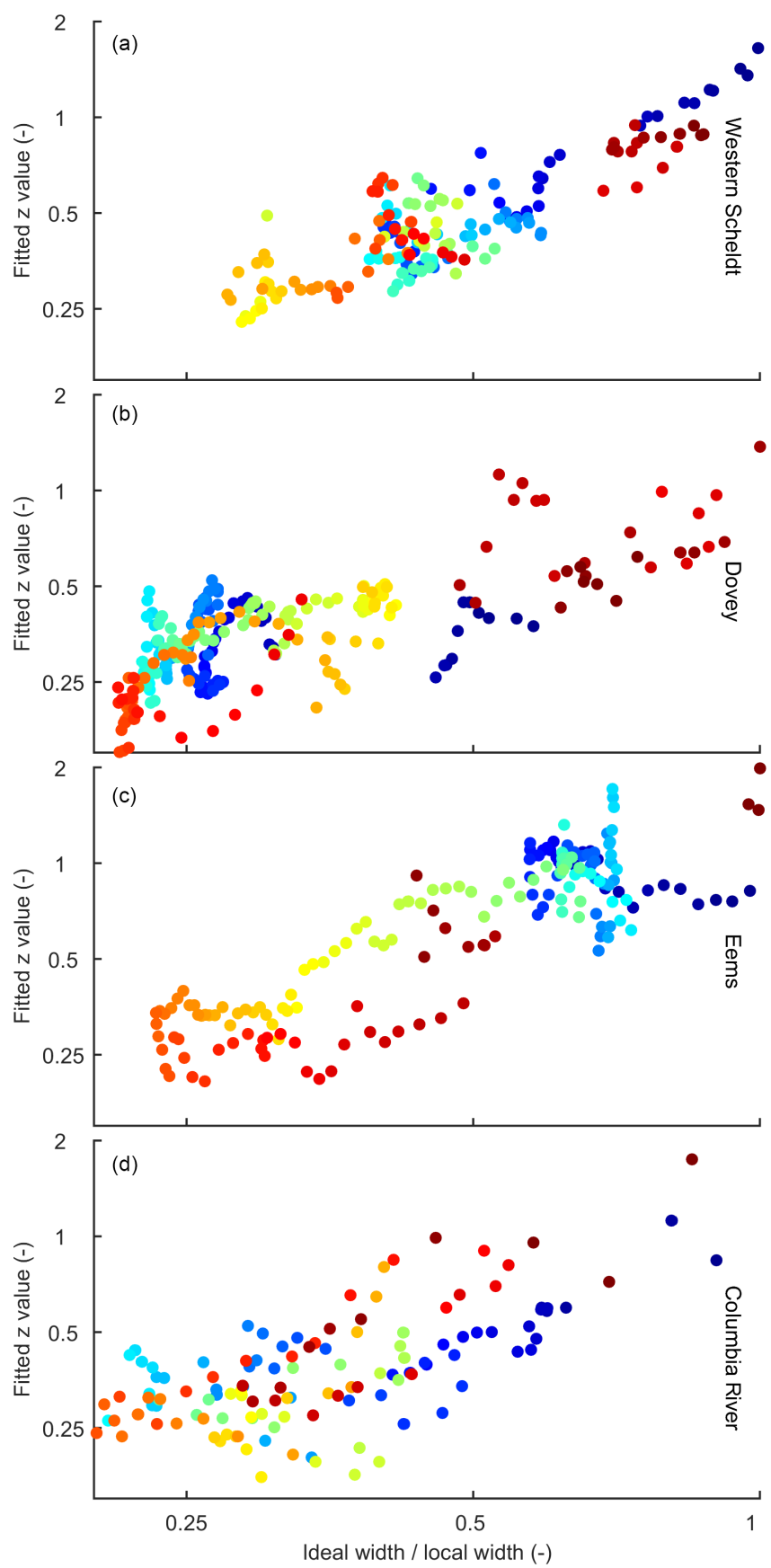

Figure 7. Fitted $z$ values as a function of deviation from the ideal width. Colours indicate the location along the estuary, with dark blue colours at the mouth transitioning into dark red colours at the landward end. Some zones show scatter in fitted $z$ values, while some other zones (e.g. green to orange to red in c) show quasiperiodic behaviour.

the resulting $z$ values at these locations do not cause major outliers, the quality of the fits is typically lower and the inverted Strahler function (Eq. 4) fitted better. These points were therefore excluded from further analysis.

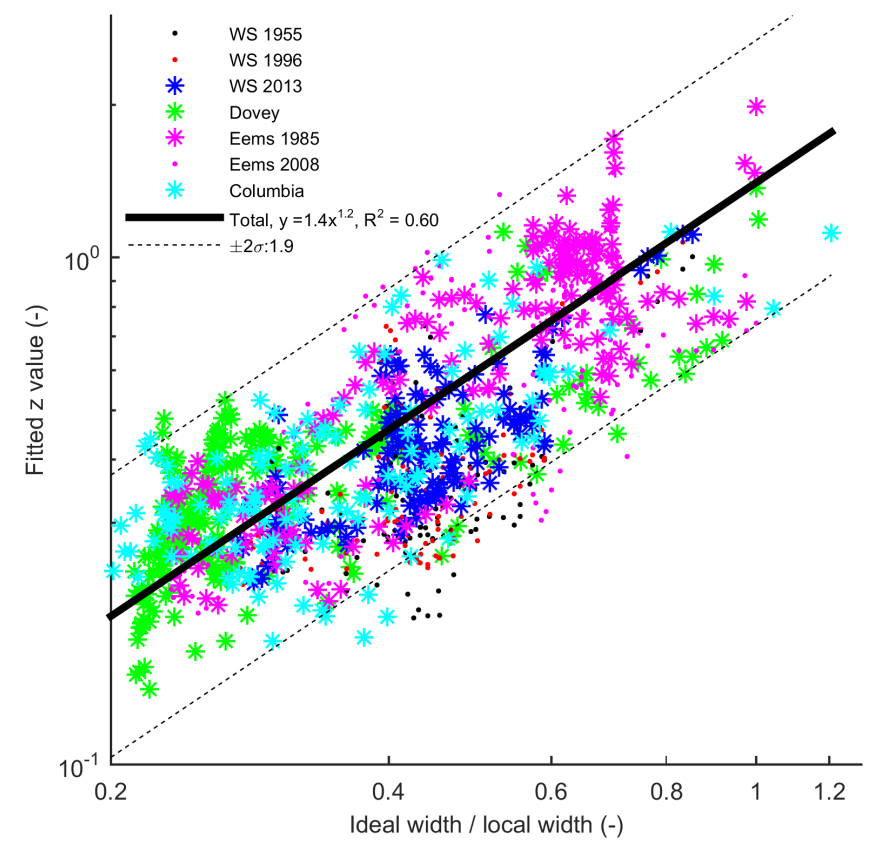

Figure 8. Fitted $z$ values of filtered data increase with the fraction of ideal width and local width, which indicates that hypsometric shapes become progressively more concave when the local width approaches the ideal width and become more convex when the local width becomes larger than the ideal width (i.e. the excess width increases). The data shown as asterisks are used for the regression. Confidence limits are plotted at 2 standard deviations above and below the regression and their multiplication factor compared to the trend is given in the legend.

The filtered data show quasi-cyclicity in along-channel hypsometry (Fig. 7). In general, the width at the mouth of the estuary and at the upstream estuary is close to ideal and the hypsometry is concave, except in systems with wide mouths and bars in the inlet. The part in between is characterised by variations in the local width and therefore gradual increases and decreases in the ratio between local width and ideal width. In some cases, quasi-cyclic loops are visible (e.g. Fig. 7c) caused by the asymmetry in bar complexes. In other cases, the points show more zigzag or clustered patterns, which indicate minor variation in the bar complexes or scatter in the fit applied to the bathymetry.

\subsection{Hypsometry predictor}

The relations between excess width and hypsometric function are similar for all estuaries, which suggests that a universal function is of value. Combining all the filtered data resulted in a regression between the extent to which an estuary deviates from the ideal shape and the predicted $z$ value in the hypsometry formulation (Fig. 8). Data from the Columbia River, Eems in 1985, the Western Scheldt in 2013 and Dovey were used to obtain this relation. Other data are shown in Fig. 8 but not used in the regression. 


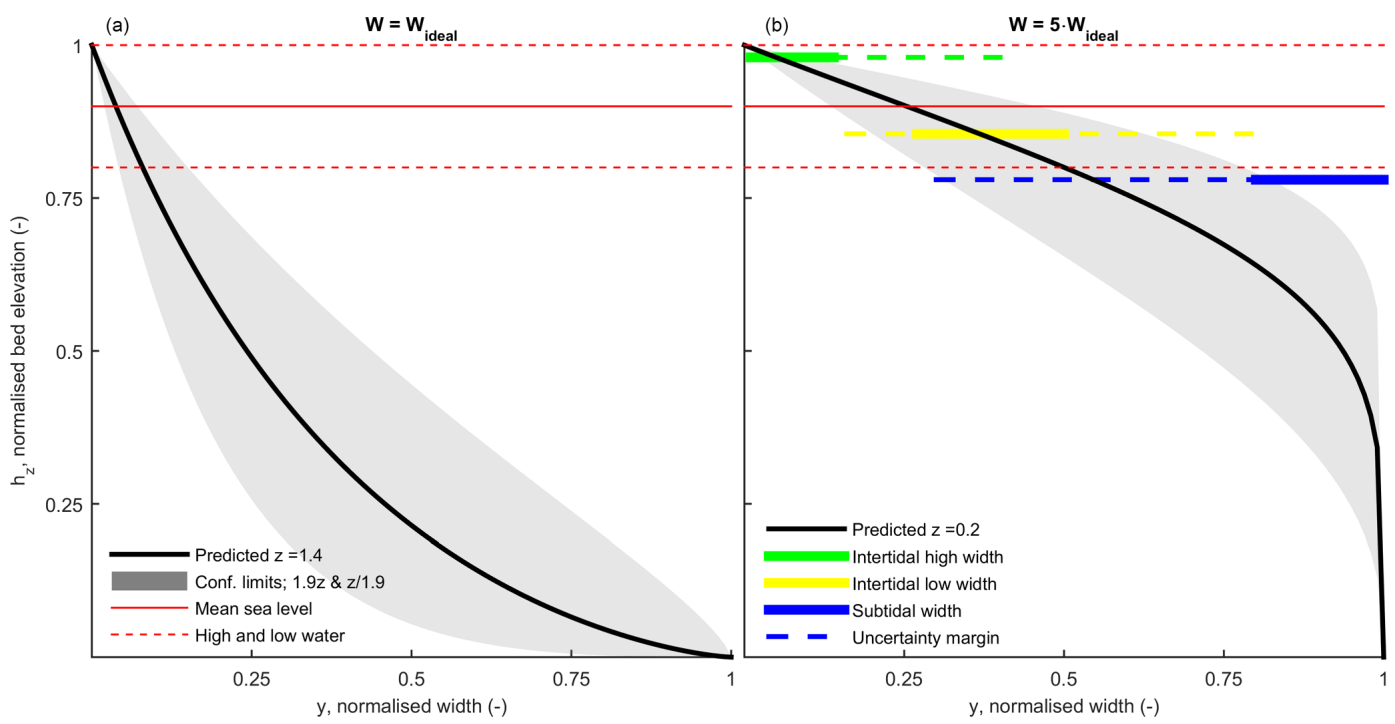

Figure 9. Illustration of uncertainty in the predicted hypsometry from Eq. (6) with uncertainty margins (Fig. 8). Resulting prediction for hypothetical location where (a) local width is equal to the ideal width and (b) local width is 5 times larger than the ideal width. Results are compared against a typical tidal range in order to show the uncertainty of predicted intertidal high width, intertidal low width and subtidal width as a fraction of the total estuary width.

These results mean that we found a predictive function for hypsometry, where $r$ is set to a constant value of 0.5 and the $z(x)$ is calculated as

$z(x)=1.4\left[\frac{W_{\text {ideal }}(x)}{W(x)}\right]^{1.2}$

in which $W_{\text {ideal }}(x)$ is the ideal estuary width (Eq. 2 ) and $W(x)$ is the measured local width. The confidence limits of the regression plot a factor of 1.9 higher and lower than the regression, which indicates that the $z$ value can be predicted within a factor of 2 (see Fig. 9 for an example of prediction with uncertainty). While not used in the regression, hypsometry from bathymetry in other years shows similar trends and scatter as the data used in the regression.

The predictor (Eq. 6) was applied to the Columbia River Estuary, Western Scheldt, Dovey and Eems to check the quality of the resulting along-channel predictions of intertidal high, intertidal low and subtidal width (Figs. 10 and 11). These zones can be derived after dimensionalising hypsometry and imposing a tidal range (Fig. 9b). For almost the entire along-channel profile, the predictions are within a factor of 2 of the measured value (Fig. 11) and the best agreement was obtained when the hypsometry was dimensionalised between the minimum and maximum measured bed level for each transect (Fig. 10).

\section{Discussion}

Results from this study illustrate that the bed-level distributions of channel and bar patterns in estuaries are topographically forced. The estuary outline that is observable from the
Table 2. Percentage of points predicted within a factor of 2 from the measured value.

\begin{tabular}{lrr}
\hline Estuary & $\%$ for subtidal & $\%$ for intertidal \\
\hline Western Scheldt & 100 & 84 \\
Columbia River & 90 & 79 \\
Dovey & 54 & 71 \\
Eems & 91 & 59 \\
\hline
\end{tabular}

surface translates into the three-dimensional patterns below the water surface. Bar-built estuaries typically have a quasiperiodic planform, in which major channel confluences occur at locations where the estuary is close to its ideal shape (Leuven et al., 2018a, b). The parts between the confluences are typically filled with intertidal bar complexes. These findings are consistent with hypsometry zonations previously found for the Western Scheldt with more concave hypsometries for channel-dominated morphology and more convex hypsometries for bar complex morphology (Toffolon and Crosato, 2007). Our cross-sectional approach additionally revealed quasi-periodic behaviour within these zones.

In contrast to an empirical description, ideally, a physicsbased determination of the hypsometry would be favourable. However, with the current state of the art of bar theory (Leuven et al., 2016) and relations for intertidal area, tidal prism, cross-sectional area and flow velocities (O'Brien, 1969; Friedrichs and Aubrey, 1988) it is not yet possible to derive a theoretical prediction of hypsometry. For example, bar theory (Seminara and Tubino, 2001; Schramkowski et al., 2002) could predict occurring bar patterns on top of an (ideal) 

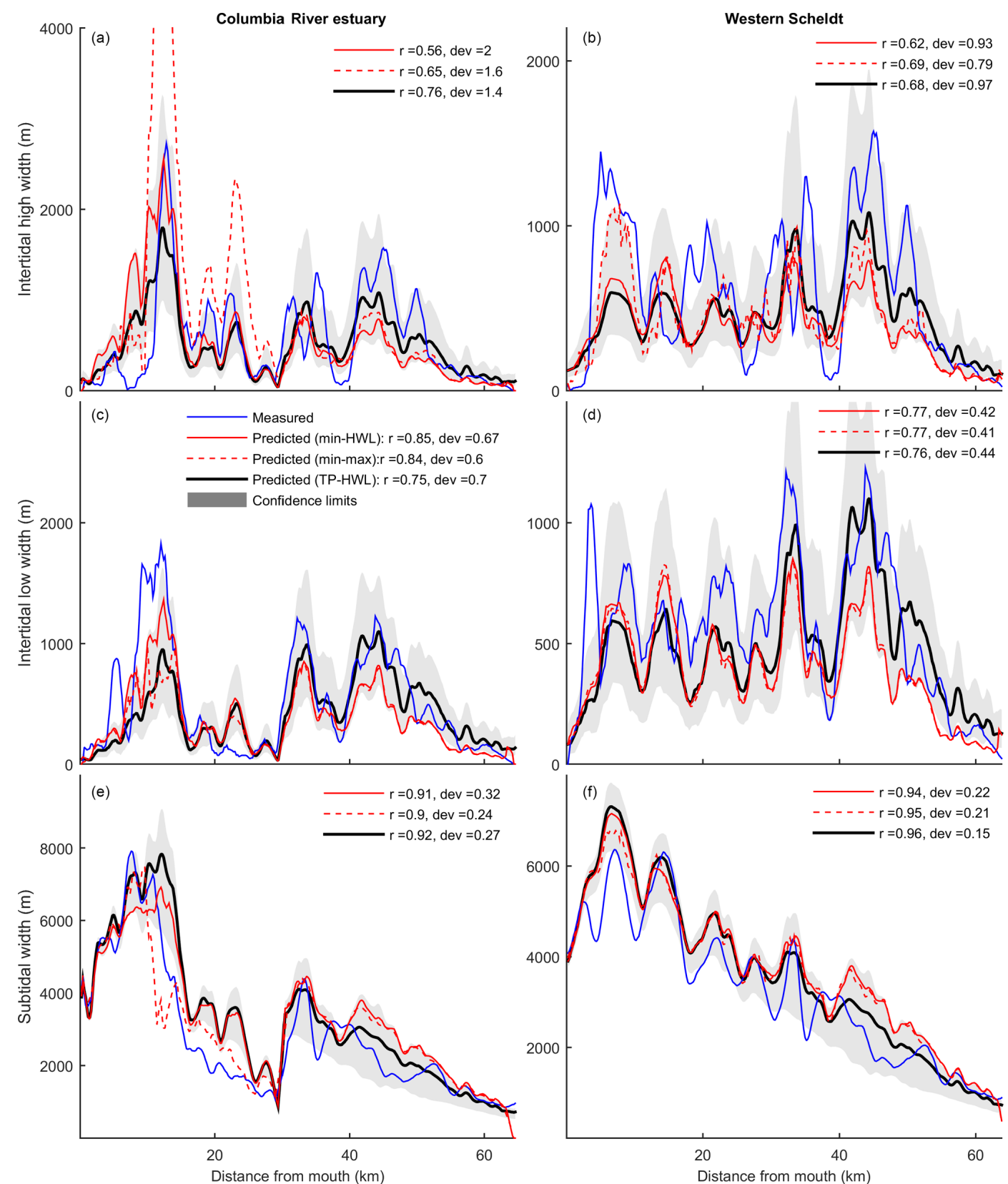

Figure 10. Comparison of measured and predicted values of intertidal high, intertidal low and subtidal width for the Columbia River Estuary $(\mathbf{a}, \mathbf{c}, \mathbf{e})$ and the Western Scheldt (b, d, f). Predicted nondimensional hypsometry was dimensionalised for each cross section using three methods (explained in Methods) and uncertainty margins are given for one of the predictions (solid black line). In the legend, $r$ indicates the Pearson product-moment correlation coefficient and "dev" the average factor of deviation between the predicted (TP-HWL) and measured lines.

estuary shape, but current theories overpredict their dimensions (Leuven et al., 2016) and it is still impossible to scale these to bed-level variations because the theories are linear. In addition to that, the resulting predictions would need to meet the requirement that the predicted bed levels and the intertidal area together lead to hydrodynamic conditions that fit the estuary as well.
Previously, hypsometry was used to summarise the geometry of entire tidal basins or estuaries (Boon and Byrne, 1981; Dieckmann et al., 1987; Townend, 2008). The whole system descriptions are consistent with the original Strahler (1952) concept of a basin hypsometry based on plan area, which is a valid description in a landform context. However, these descriptions oversimplify the along-channel variability in estuaries that are relatively long. These estuaries typi- 


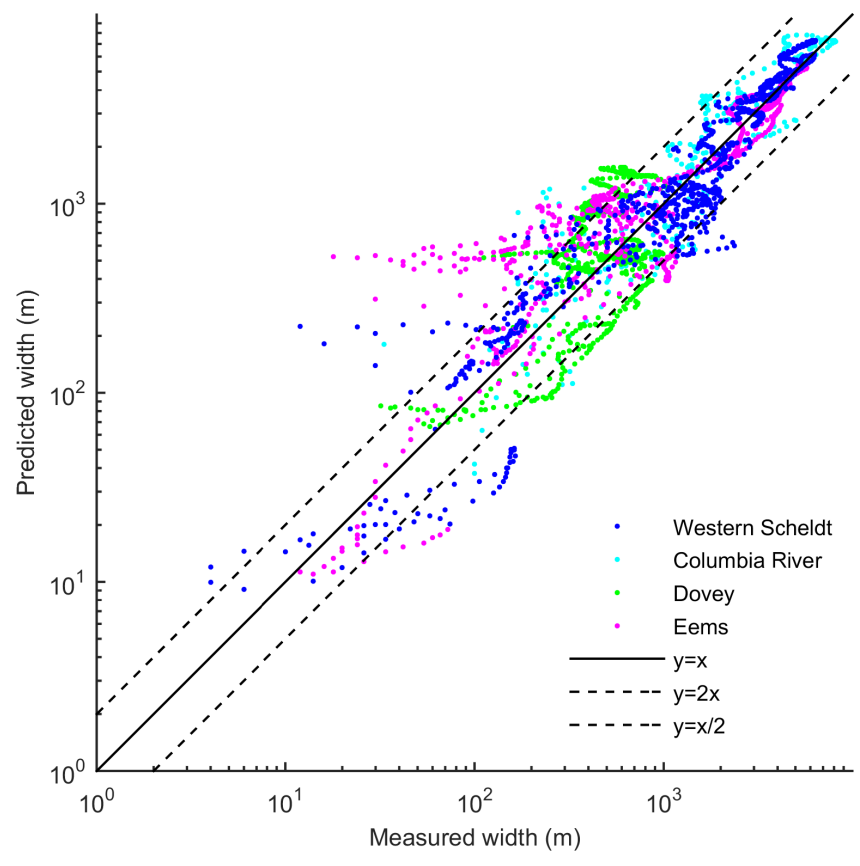

Figure 11. Comparison of measured and predicted width of intertidal and subtidal width. The (solid) line of equality indicates a perfect fit and dashed lines indicate a deviation of a factor of 2 . The percentage of measurements within these margins is indicated in Table 2.

cally have a linear bed profile varying from an along-channel constant depth to strongly linear sloping (e.g. the Mersey in the UK). In the latter case, the elevation at which subtidal and intertidal area occurs varies significantly along-channel (Blott et al., 2006). Additionally, friction and convergence may cause the tidal range to either dampen or amplify, causing variation in tidal elevation, subtidal area and tidal prism (Savenije, 2006). Consequently, the along-channel cross section hypsometry should be assumed to be relative to an along-channel varying high water level or mean sea level rather than an along-channel fixed vertical datum. Interpreting these along-channel variations remains an open question because of the reasons outlined above. Nevertheless, if desired, along-channel varying hypsometry predictions can be converted into one single summarising curve (Fig. 12), which shows that the basin hypsometry can also be predicted when limited data are available.

Our results show that hypsometry is not only a tool to predict morphology when limited data are available, but that hypsometry can also be used to reduce a large dataset of bathymetry and to study the evolution of bathymetry over time. In the case of Strahler (1952), hypsometry fits result in along-channel profiles of $z$ and $r$ values, but in practice any function or shape could be fitted. For example, the locations along the Western Scheldt where major dredging and dumping took place showed a weaker correlation with the original Strahler (1952) shape (Fig. 13). In these cases, fits with

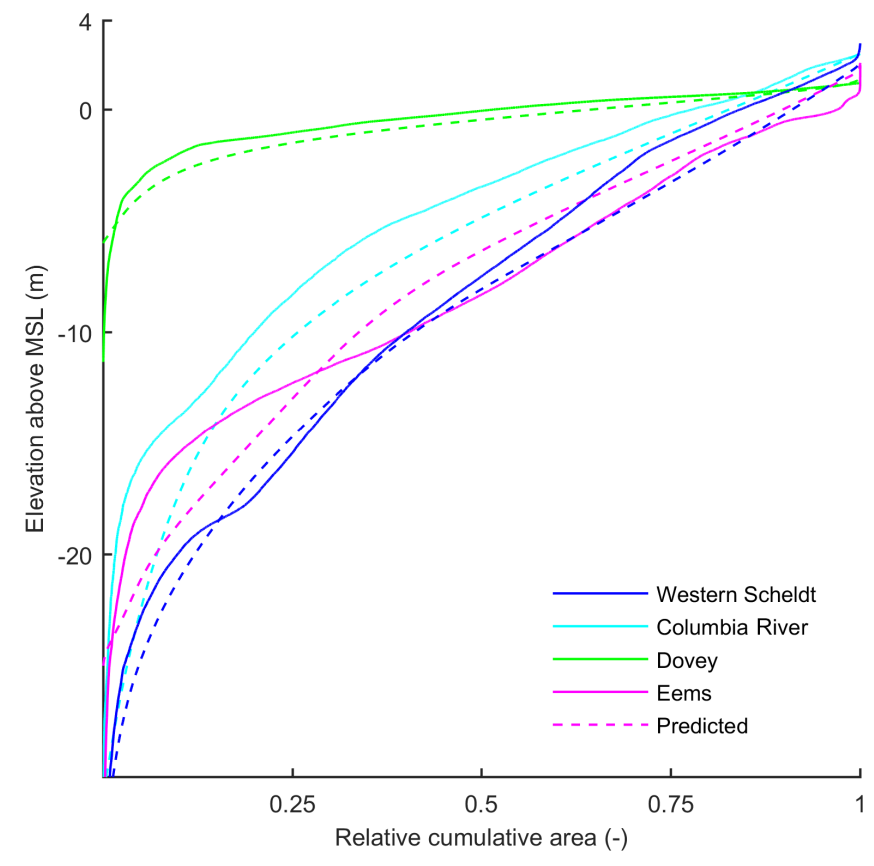

Figure 12. Hypsometry as summarised in a single curve for the entire estuaries. Solid lines are measured from bathymetry, and dashed lines are based on the predictions.

higher quality (lower RMSE) were obtained when we used the inverted hypsometric function (Eq. 4) (Fig. 13b, e). So in practice, one could fit a range of different hypsometry shapes and subsequently find out which of these shapes fit best on the dataset used. It can indicate that certain parts along the estuary require a separate hypsometric description. The fitting parameters are a method to describe the along-channel variation (Fig. 13b, d). Hypsometry can be fitted to compare data from nature, physical experiments and numerical modelling and subsequently study, for example, the effect of vegetation, cohesive mud and the influence of management on these systems.

\subsection{Implications for management of estuaries}

In many estuaries from around the world, subtidal channels are used as shipping fairways, while the intertidal bars (or shoals) form valuable ecological habitats (e.g. Bouma et al., 2005). For example in the Western Scheldt, the shipping fairway is now maintained at a depth of $14.5 \mathrm{~m}$ below the lowest astronomical tide (de Vriend et al., 2011; Depreiter et al., 2012). With empirical hypsometry predictions, we can estimate the width below a certain depth required for shipping, which gives estimates of what volume to dredge and at what locations along the estuary, which is relevant for the construction of future shipping fairways in estuaries for which we may have limited data.

In contrast, low-dynamic intertidal areas are valuable ecological habitats; for example, for the Western Scheldt there is 


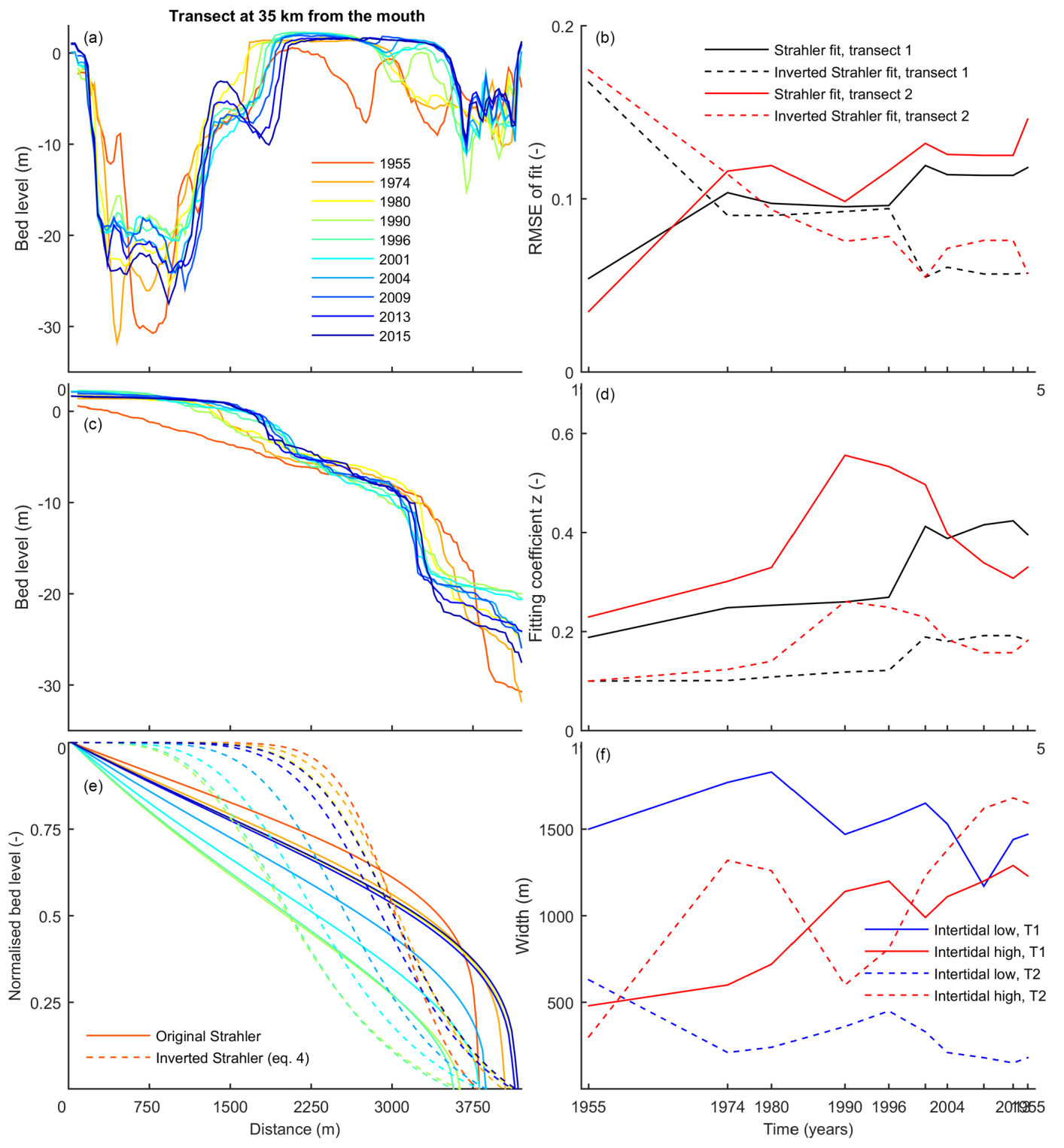

Figure 13. (a) Evolution of a cross section in the Western Scheldt where it has been significantly dredged and dumped (the Drempel van Hansweert). (c) Measured hypsometric profiles of the same time steps at the same cross section. (e) Best-fit hypsometries using the original Strahler equation (solid) and inverted Strahler function (Eq. 4) (dashed). (b) The quality of the two types of fits shows that the shape of the best-fitting hypsometric curve changes from the original Shrahler to the inverted equation in the 1970s-1980s. An additional transect is added in the panels on the right. (d) Fitting coefficients for $z$ increase over time for both hypsometry types and both transects. (f) Intertidal high area increased over this period, while intertidal low area remained constant (transect 1) or decreased (transect 2).

an obligation to maintain a certain amount of intertidal area (Depreiter et al., 2012). Previously, Townend (2008) showed that basin hypsometry can be a tool to design breaches in managed realignment sites and can provide an indication of habitat composition. Hypsometry analysis per cross section shows that estuary outline translates into intertidal area, which implies that locations where the estuary is relatively wide have a relatively wide intertidal area. The ecological value is determined by the area of low-dynamical shallow water and intertidal areas (for settling and feeding) (Depre- iter et al., 2012). This means that the edges should neither become steeper nor higher (leading to permanent dry fall) or deeper. Hypsometry fits (in the case of available data) or predictions (in the case of limited data) can indicate which locations along the estuary have a risk to transform away from low-dynamic area or have the potential to become lowdynamic area by the suppletion of dredged sediment.

The occurrence of vegetation species depends on bed elevation, salinity, maximum flow velocity and sediment type (de Jong, 1999; Gurnell et al., 2012). Even though predicted 


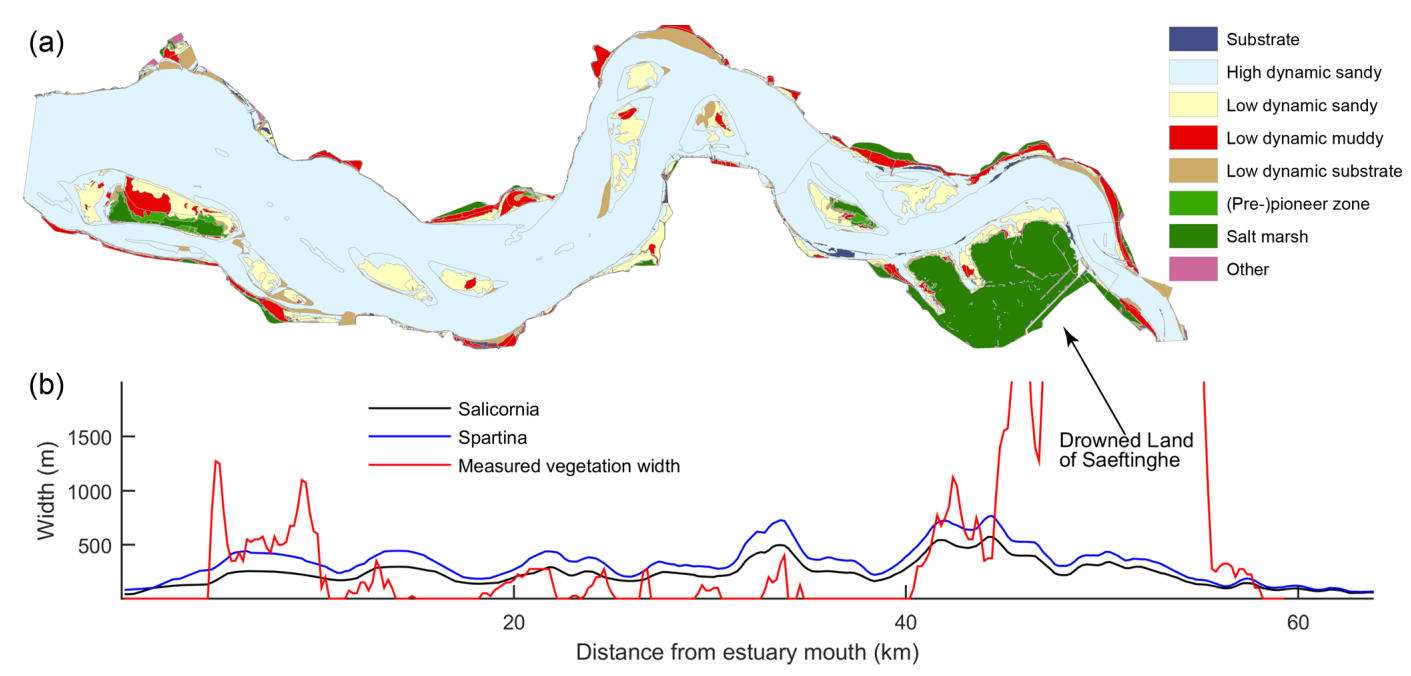

Figure 14. (a) Ecotope map of the Western Scheldt (2012) obtained from Rijkswaterstaat. (b) Prediction of the width in which Salicornia (black) and Spartina (blue) can occur when assuming that Spartina occurs between MSL and $1.5 \mathrm{~m}$ above and Salicornia occurs between 1.0 and $2.5 \mathrm{~m}$, while ignoring velocity, salinity and sediment type constraints. Red line indicates measured width of vegetation based on ecotope map. The Drowned Land of Saeftinghe is excluded in the predictions because the high water line was the boundary of the analysed bathymetry, while it is included in the measured data.

hypsometry only gives bed elevations, a comparison of the height interval in which Salicornia and Spartina can occur (Mckee and Patrick, 1988; Davy et al., 2001; van Braeckel et al., 2008) showed similar trends and the same order of magnitude as the measured vegetation from ecotope maps of the Western Scheldt in 2012 (Fig. 14). Some underpredictions arise in parts along the estuary where bed elevations above the high water level occur, such as at the Drowned Land of Saeftinghe. However, in general, the vegetation width is overpredicted because (1) hypsometry is stretched between the high water line and channel depth and (2) other constraining biotic and abiotic factors were excluded.

\section{Conclusions}

We studied the relation between the along-channel planform geometry of sandy estuaries and their hypsometry, which characterises the distribution of along-channel and crosschannel bed levels. The vertical dimensions were found to relate to the horizontal dimensions. In other words, the degree to which the estuary width deviates from an ideal converging estuary shape is reflected in the occurring hypsometry. At locations where the width is much larger than ideal, convex hypsometric shapes are observed, contrary to the locations where the estuary width is close to ideal, where concave hypsometric shapes are observed. In between these extreme endmembers, a gradual transition with quasi-periodic variation was observed. This implies that it is possible to predict the along-channel varying hypsometry of estuaries, which is relevant for estuaries for which limited data are available. To obtain broad-brush estimates of the occurring bed levels, only the estuary outline and a typical tidal amplitude are re- quired. The predictions can be used to study the presence and evolution of intertidal area, which forms valuable ecological habitats, and to get estimates of typical volumes that might need to be dredged when constructing shipping fairways.

Data availability. Bathymetry was obtained from Rijkswaterstaat for the Western Scheldt and Eems estuary, from Natural Resources Wales via Emmer Litt for the Dovey and from the Lower Columbia Estuary Partnership for the Columbia River Estuary.

Author contributions. The authors contributed in the following proportions to conception and design, data collection and processing, analysis and conclusions, and paper preparation: JRFWL (70, $65,75,70 \%)$, SS (10, 30, 15, $15 \%)$, MGK $(20,5,10,15 \%)$.

Competing interests. The authors declare that they have no conflict of interest.

Acknowledgements. This research was supported by Future Deltas, Utrecht University (grant to JRFWL) and by the Dutch Technology Foundation TTW (grant Vici 016.140.316/13710 to MGK), which is part of the Netherlands Organisation for Scientific Research (NWO) and is partly funded by the Ministry of Economic Affairs. This work is part of the $\mathrm{PhD}$ research of JRFWL. We acknowledge the data processing contribution by Andy Bruijns as part of his MSc guided research. Reviews by Ian Townend and one anonymous reviewer helped to improve the paper. 
Edited by: Daniel Parsons

Reviewed by: Ian Townend and one anonymous referee

\section{References}

Blott, S. J., Pye, K., van der Wal, D., and Neal, A.: Long-term morphological change and its causes in the Mersey Estuary, NW England, Geomorphology, 81, 185-206, 2006.

Bolle, A., Wang, Z. B., Amos, C., and de Ronde, J.: The influence of changes in tidal asymmetry on residual sediment transport in the Western Scheldt, Cont. Shelf Res., 30, 871-882, 2010.

Boon, J. D.: Tidal discharge asymmetry in a salt marsh drainage system, Limnol. Oceanogr., 20, 71-80, 1975.

Boon, J. D. and Byrne, R. J.: On basin hyposmetry and the morphodynamic response of coastal inlet systems, Marine Geol., 40, 27-48, https://doi.org/10.1016/0025-3227(81)90041-4, 1981.

Bouma, H., de Jong, D., Twisk, F., and Wolfstein, K.: A Dutch Ecotope system for coastal waters (ZES. 1), To map the potential occurence of ecological communities in Dutch coastal and transitional waters, Tech. rep., Rijkswaterstaat, Report RIKZ/2005.024, 2005.

Braat, L., van Kessel, T., Leuven, J. R. F. W., and Kleinhans, M. G.: Effects of mud supply on large-scale estuary morphology and development over centuries to millennia, Earth Surf. Dynam., 5, 617-652, https://doi.org/10.5194/esurf-5-617-2017, 2017.

Dam, G., van der Wegen, M., Roelvink, D., Labeur, R., and Bliek, B.: Simulation of long-term morphodynamics of the Western Scheldt, in: 36st IAHR congress, The Hague, Netherlands, 2015.

Davies, G. and Woodroffe, C. D.: Tidal estuary width convergence: Theory and form in North Australian estuaries, Earth Surf. Proc. Land., 35, 737-749, https://doi.org/10.1002/esp.1864, 2010.

Davy, A. J., Bishop, G. F., and Costa, C. S. B.: Salicornia L.(Salicornia pusilla J. woods, S. ramosissima J. woods, S. europaea L., S. obscura PW ball \& tutin, S. nitens PW ball \& tutin, S. fragilis PW ball \& tutin and S. dolichostachya moss), J. Ecol., 89, 681-707, 2001.

de Haas, T., Pierik, H., van der Spek, A., Cohen, K., van Maanen, B., and Kleinhans, M.: Holocene evolution of tidal systems in The Netherlands: Effects of rivers, coastal boundary conditions, eco-engineering species, inherited relief and human interference, Earth-Sci. Rev., 177, 139-163, https://doi.org/10.1016/j.earscirev.2017.10.006, 2017.

de Jong, D.: Ecotopes in the Dutch marine tidal waters: a proposal for a classification of ecotopes and a method to map them, Tech. rep., Rijkswaterstaat, Report RIKZ/99.017, 1999.

de Vet, P., van Prooijen, B., and Wang, Z.: The differences in morphological development between the intertidal flats of the Eastern and Western Scheldt, Geomorphology, 281, 31-42, 2017.

de Vriend, H. J., Wang, Z. B., Ysebaert, T., Herman, P. M., and Ding, P.: Eco-morphological problems in the Yangtze Estuary and the Western Scheldt, Wetlands, 31, 1033-1042, https://doi.org/10.1007/s13157-011-0239-7, 2011.

Depreiter, D., Sas, M., Beirinckx, K., and Liek, G.-J.: Flexible Disposal Strategy: monitoring as a key to understanding and steering environmental responses to dredging and disposal in the Scheldt Estuary, Tech. rep., International Marine \& Dredging Consultants, 2012.
Dieckmann, R., Osterthun, M., and Partenscky, H.-W.: Influence of water-level elevation and tidal range on the sedimentation in a German tidal flat area, Prog. Oceanogr., 18, 151-166, 1987.

Dronkers, J.: Convergence of estuarine channels, Cont. Shelf Res., 144, 120-133, https://doi.org/10.1016/j.csr.2017.06.012, 2017.

Eysink, W.: Morphologic response of tidal basins to changes, Coast. Eng. Proc., 1, 1948-1961, https://doi.org/10.1061/9780872627765.149, 1990.

Friedrichs, C. T.: Stability shear stress and equilibrium crosssectional geometry of sheltered tidal channels, J. Coast. Res., 11, 1062-1074, 1995.

Friedrichs, C. T.: Barotropic tides in channelized estuaries, Cont. Iss. Est. Phys., 27-61, 2010.

Friedrichs, C. T. and Aubrey, D. G.: Non-linear tidal distortion in shallow well-mixed estuaries: a synthesis, Estuar. Coast. Shelf Sci., 27, 521-545, 1988.

Gardiner, S., Nicholls, R., and Tanton, T.: Management Implications of Flood/Ebb tidal dominance: its influence on saltmarsh and intertidal habitat stability in Poole Harbour, in: Littoral 2010-Adapting to Global Change at the Coast: Leadership, Innovation, and Investment, p. 06004, EDP Sciences, 2011.

Gisen, J. I. A. and Savenije, H. H.: Estimating bankfull discharge and depth in ungauged estuaries, Water Resour. Res., 51, 2298 2316, https://doi.org/10.1002/2014WR016227, 2015.

Gurnell, A. M., Bertoldi, W., and Corenblit, D.: Changing river channels: The roles of hydrological processes, plants and pioneer fluvial landforms in humid temperate, mixed load, gravel bed rivers, Earth-Sci. Rev., 111, 129-141, https://doi.org/10.1016/j.earscirev.2011.11.005, 2012.

Hey, R. D. and Thorne, C. R.: Stable channels with mobile gravel beds, J. Hydr. Eng., 112, 671-689, https://doi.org/10.1061/(ASCE)0733-9429(1986)112:8(671), 1986.

Hu, Z., Belzen, J., Wal, D., Balke, T., Wang, Z. B., Stive, M., and Bouma, T. J.: Windows of opportunity for salt marsh vegetation establishment on bare tidal flats: The importance of temporal and spatial variability in hydrodynamic forcing, J. Geophys. Res.Biogeosci., 120, 1450-1469, 2015.

Jeuken, M. and Wang, Z.: Impact of dredging and dumping on the stability of ebb-flood channel systems, Coast. Eng., 57, 553-566, 2010.

Kirby, R.: Practical implications of tidal flat shape, Cont. Shelf Res., 20, 1061-1077, 2000.

Kleinhans, M. G. and van den Berg, J. H.: River channel and bar patterns explained and predicted by an empirical and a physics-based method, Earth Surf. Proc. Land., 36, 721-738, https://doi.org/10.1002/esp.2090, 2011.

Langbein, W.: The hydraulic geometry of a shallow estuary, Hydrol. Sci. J., 8, 84-94, https://doi.org/10.1080/02626666309493340, 1963.

Lanzoni, S. and D'Alpaos, A.: On funneling of tidal channels, J. Geophys. Res.-Earth, 120, 433-452, https://doi.org/10.1002/2014JF003203, 2015.

Leopold, L. B. and Maddock Jr, T.: The Hydraulic Geometry of Stream Channels and Some Physiographic Implications, Tech. rep., U.S. Geological Survey, Professional Paper 252, 1953.

Lesourd, S., Lesueur, P., Brun-Cottan, J.-C., Auffret, J.-P., Poupinet, N., and Laignel, B.: Morphosedimentary evolution of the 
macrotidal Seine estuary subjected to human impact, Estuar. Coast., 24, 940-949, 2001.

Leuven, J. R. F. W., Kleinhans, M. G., Weisscher, S. A. H., and van der Vegt, M.: Tidal sand bar dimensions and shapes in estuaries, Earth-Sci. Rev., 161, 204-233, https://doi.org/10.1016/j.earscirev.2016.08.004, 2016.

Leuven, J. R. F. W., Haas, T., Braat, L., and Kleinhans, M. G.: Topographic forcing of tidal sand bar patterns for irregular estuary planforms, Earth Surf. Proc. Land., 43, 172-186, https://doi.org/10.1002/esp.4166, 2018a.

Leuven, J. R. F. W., Braat, L., van Dijk, W. M., de Haas, T., and Kleinhans, M. G.: Growing forced bars determine non-ideal estuary planform Journal of Geophysical Research: Earth Surface (revision submitted, preprint: 10.31223/osf.io/hj27m), 2018b.

Mckee, K. L. and Patrick, W.: The relationship of smooth cordgrass (Spartina alterniflora) to tidal datums: a review, Estuaries, 11, 143-151, 1988.

Moore, R. D., Wolf, J., Souza, A. J., and Flint, S. S.: Morphological evolution of the Dee Estuary, Eastern Irish Sea, UK: a tidal asymmetry approach, Geomorphology, 103, 588-596, 2009.

O'Brien, M. P.: Equilibrium flow areas of inlets on sandy coasts, in: J. Geol. Soc. of the waterways and harbors division, Proceedings of the American Society of Civil Engineers, 43-52, ASCE, https://doi.org/10.1061/9780872620087.039, 1969.

O'Connor, B.: Short and long term changes in estuary capacity, J. Geol. Soc., 144, 187-195, 1987.

Pillsbury, G.: Tidal Hydraulics. Revised Edition, Corps of Engineers, US Army, May, 1956.

Plancke, Y. and Vos, G. R.: Sediment transport in the Scheldeestuary: a comparison between measurements, transport formula and numerical models, in: Proceedings of the 4th IAHR Europe Congress, Liege, Belgium, 27-29 July 2016: Sustainable Hydraulics in the Era of Global Change, 498-503, 2016.

Savenije, H. H.: Salinity and tides in alluvial estuaries, Elsevier, 2006.

Savenije, H. H.: Prediction in ungauged estuaries: an integrated theory, Water Resour. Res., 51, 2464-2476, https://doi.org/10.1002/2015WR016936, 2015.

Schramkowski, G., Schuttelaars, H., and De Swart, H.: The effect of geometry and bottom friction on local bed forms in a tidal embayment, Cont. Shelf Res., 22, 1821-1833, https://doi.org/10.1016/S0278-4343(02)00040-7, 2002.

Seminara, G. and Tubino, M.: Sand bars in tidal channels. Part 1. Free bars, J. Fluid Mech., 440, 49-74, https://doi.org/10.1017/S0022112001004748, 2001.

Strahler, A. N.: Hypsometric (area-altitude) analysis of erosional topography, Geol. Soc. Am. Bull., 63, 1117-1142, https://doi.org/10.1130/00167606(1952)63[1117:HAAOET]2.0.CO;2, 1952.

Swinkels, C. M., Jeuken, C. M., Wang, Z. B., and Nicholls, R. J.: Presence of connecting channels in the Western Scheldt Estuary, J. Coast. Res., 627-640, 2009.
Toffolon, M. and Crosato, A.: Developing macroscale indicators for estuarine morphology: The case of the Scheldt Estuary, J. Coast. Res., 23, 195-212, 2007.

Toffolon, M. and Lanzoni, S.: Morphological equilibrium of short channels dissecting the tidal flats of coastal lagoons, J. Geophys. Res.-Earth, 115, F04036, https://doi.org/10.1029/2010JF001673, 2010.

Townend, I.: An exploration of equilibrium in Venice Lagoon using an idealised form model, Cont. Shelf Res., 30, 984-999, 2010.

Townend, I.: The estimation of estuary dimensions using a simplified form model and the exogenous controls, Earth Surf. Proc. Land., 37, 1573-1583, https://doi.org/10.1002/esp.3256, 2012.

Townend, I. H.: Hypsometry of estuaries, creeks and breached sea wall sites, P. I. Civil Eng.-Mar. En., 161, 23-32, https://doi.org/10.1680/maen.2008.161.1.23, 2008.

van Braeckel, A., Vandevoorde, B., and van den Bergh, E.: Schorecotopen van de Schelde. Aanzet tot de ontwikkeling van één schorecotopenstelsel voor Vlaanderen en Nederland, Instituut voor Natuur-en Bosonderzoek, 2008.

van de Lageweg, W. I., Dijk, W. M., Box, D., and Kleinhans, M. G.: Archimetrics: a quantitative tool to predict three-dimensional meander belt sandbody heterogeneity, The Depositional Record, https://doi.org/10.1002/dep2.12, 2, 22-46, 2016.

van der Wegen, M. and Roelvink, J.: Long-term morphodynamic evolution of a tidal embayment using a two-dimensional, process-based model, J. Geophys. Res.-Oceans, 113, C03016, https://doi.org/10.1029/2006JC003983, 2008.

van der Wegen, M. and Roelvink, J.: Reproduction of estuarine bathymetry by means of a process-based model: Western Scheldt case study, the Netherlands, Geomorphology, 179, 152-167, https://doi.org/10.1016/j.geomorph.2012.08.007, 2012.

van Maren, D., Van Kessel, T., Cronin, K., and Sittoni, L.: The impact of channel deepening and dredging on estuarine sediment concentration, Cont. Shelf Res., 95, 1-14, https://doi.org/10.1016/j.csr.2014.12.010, 2015.

Wang, Z. and Winterwerp, J.: Impact of dredging and dumping on the stability of ebb-flood channel systems, in: Proceedings of the 2nd IAHR symposium on River, Coastal and Estuarine Morphodynamics, 515-524, 2001.

Wang, Z., Jeuken, M., Gerritsen, H., De Vriend, H., and Kornman, B.: Morphology and asymmetry of the vertical tide in the Westerschelde estuary, Cont. Shelf Res., 22, 2599-2609, 2002.

Wang, Z., Van Maren, D., Ding, P., Yang, S., Van Prooijen, B., De Vet, P., Winterwerp, J., De Vriend, H., Stive, M., and He, Q.: Human impacts on morphodynamic thresholds in estuarine systems, Cont. Shelf Res., 111, 174-183, 2015.

Wolanski, E. and Elliott, M.: Estuarine ecohydrology: an introduction, Elsevier, Amsterdam, 1-316, 2015. 